\title{
Self-Reported Experiences, Attitudes and Expectations of Infant Contacts in Medical Students; A Cross-Sectional Study in Ten Years' Interval
}

\author{
A. Marita Valkama ${ }^{1,2,3}{ }^{*}$, Mailis Mäkelä1, Jarmo Salo',2, Marja Ojaniemi ${ }^{1,2,3}$ \\ ${ }^{1}$ Department of Children and Adolescents, Oulu University Hospital, Oulu, Finland \\ ${ }^{2}$ PEDEGO Research Center, University of Oulu, Oulu, Finland \\ ${ }^{3}$ Medical Research Center, University of Oulu, Oulu, Finland \\ Email: ^arjamaritavalkama@gmail.com, ^marita.valkama@ppshp.fi
}

How to cite this paper: Valkama, A.M., Mäkelä, M., Salo, J. and Ojaniemi, M. (2017) Self-Reported Experiences, Attitudes and Expectations of Infant Contacts in Medical Students; A Cross-Sectional Study in Ten Years' Interval. International Journal of Clinical Medicine, 8, 216- 226.

https://doi.org/10.4236/ijcm.2017.84021

Received: March 16, 2017

Accepted: April 27, 2017

Published: April 30, 2017

Copyright $\odot 2017$ by authors and Scientific Research Publishing Inc. This work is licensed under the Creative Commons Attribution International License (CC BY 4.0).

http://creativecommons.org/licenses/by/4.0/

(c) (i) Open Access

\begin{abstract}
Introduction: Medical students worked earlier as independent practitioners before paediatrics courses. Now it is denied. We evaluated students' experiences of infant contacts before and after the change. Methods: A cross-sectional questionnaire study consists of students attending paediatrics courses at University of Oulu in 2004-2006 and 2014-2015. Results: 229 of 241 (95.0\%) students in the first cohort and 236 of 258 (91.5\%) in the second completed the questionnaire. The mean (SD) age of the students was $25.1(3.0)$ and $25.9(3.0)(\mathrm{p}=0.040)$. In both cohorts two thirds of the students were familiar with holding infants in the lap, but two thirds had never bathed an infant. A half of males and one third of females had never fed an infant. Students approximated to manage with infants and believed to manage increased with age in both cohorts $(\mathrm{p}<0.001$ vs. $\mathrm{p}=$ 0.019 ). Students' perspective towards pediatrics as a future carrier choice declined from $30.3 \%$ to $22.0 \%$. Conclusions: Students' experiences in handling and care of infants are quite low before paediatrics courses. The denial not to work as independent practitioner before paediatric courses did not decrease experiences. Medical students are motivated to have infant experiences in practice.
\end{abstract}

\section{Keywords}

Medical Students, Experiences, Infants

\section{Introduction}

Undergraduate medical students used to work as independent practitioners in 
healthcare centres in Finland after the fourth study year up to the late 2010'. After that the possibility was denied and only working under guidance and mainly in hospitals remained. The core teaching in paediatrics takes place during the fifth study year. The ten-week paediatrics courses include lectures, small group sessions, home study, medical rounds and clinical skills training with patients on wards and in outpatient clinics and emergency units. Teaching and studying cover basic awareness to deal with a great variety of conditions and diseases connected to neonates, infants, toddlers, older children and teenagers. Medical students have two-week periods on different paediatric wards at Oulu University Hospital and they meet infants in all paediatric areas. Clinical skills for care of the youngest infants are developed mainly in neonatal care wards. During the neonatal care period the students should practice their skills in handling and examining neonates and young infants. Medical students participate in tutorial education sessions of two hours in small groups of 8 to 12 students and they take part in normal morning rounds. Parents are normally being present during daytime rounds and during examination of their own infants.

Walters et al. reported the results of a study, where basics of infant care were taught in a 1-day nurse-medical student preceptor program for $3^{\text {rd }}$ year medical students. Although this was a very limited intervention, it significantly increased students' experiences in infant daily care procedures, including dressing an infant, changing a nappy, bathing and feeding an infant [1]. It is not known how the denial of permission to work as an independent practitioner in health care centres before clinical paediatrics courses of the fifth study year affects to experiences of young infant contacts among undergraduate medical students. We evaluated students' experiences, attitudes and expectations of young infant contacts before their clinical paediatrics courses at Oulu University Hospital by a questionnaire in ten years' interval.

\section{Methods}

Medical students attending their clinical paediatrics courses at Oulu University Hospital from autumn 2004 to autumn 2006 (Cohort 1) and a comparative control amount of students from spring 2014 to autumn 2015 (Cohort 2) were invited to complete a questionnaire about their young infant contacts. Because of the nature of the study of the Ethics Committee was not used. This study accords with the Declaration of Helsinki.

\subsection{Questionnaires}

Medical students were asked to complete the questionnaire voluntarily and anonymously. They were asked to describe their situation before the beginning of their paediatrics courses. The questionnaire included the background data, students' experiences of caring for infants [1], and knowledge of their attitudes and expectations of ability to manage with infants. We also asked if students had worked as independent practitioners in hospitals or health care centres before the courses. We also asked if they were interested in a career in paediatrics. After 
questions there was space for the students to wish what kind of knowledge or teaching they are waiting for infant contacts. Table 1 includes the structured questionnaire protocol.

\subsection{Statistics}

The questionnaire data were statistically analysed by using the Statistical Package for the Social Sciences (SPSS) 22.0. Means, standard deviations (SDs) or medians (range) was used. 95\% confidence intervals when possible were calculated and the significance set at $\mathrm{p}<0.050$. In analysis of group differences, nonparametric (Chi-Square) and parametric (Independent sample's $\mathrm{t}$ ) tests were used.

\section{Results}

There were 241 medical students in the Cohort 1 participating the five consecutive paediatrics courses from autumn 2004 to the end of 2006 and 258 students in the Cohort 2 participating in four consecutive courses from spring 2014 to the end of the year 2015 at Oulu University Hospital. 229 students (95.0\%) of the Cohort 1 and 238 (91.5\%) of the Cohort 2 completed the questionnaire. The percentage of the male students in the cohorts was $32.3 \%$ and $48.7 \%$. Gender difference between the study cohorts changed significantly $(\mathrm{p}<0.001)$.

Table 1. Medical students' questionnaire protocol.

\begin{tabular}{|c|c|}
\hline $\begin{array}{l}\text { Background; } \\
\text { Complete }\end{array}$ & $\begin{array}{l}\text { - } \text { Age } \\
\text { - } \text { Gender } \\
\text { - Home town origin } \\
\text { - Number of siblings in one's native family } \\
\text { - Number of offspring }\end{array}$ \\
\hline $\begin{array}{l}\text { Care and handling } \\
\text { of infants; } \\
\text { Encircle the frequency }\end{array}$ & $\begin{array}{l}\text { - } \quad \text { Holding in lap; No-over } 5 \text { times } \\
\text { - } \quad \text { Dressing an infant; No-over } 5 \text { times } \\
\text { - } \quad \text { Changing a nappy; No-over } 5 \text { times } \\
\text { - } \quad \text { Bathing an infant; No-over } 5 \text { time } \\
\text { - } \quad \text { Feeding an infant; No-breast/ bottle-solid food }\end{array}$ \\
\hline $\begin{array}{l}\text { Experiences, Attitudes } \\
\qquad \text { and } \\
\text { Expectations; } \\
\text { Cross alternatives you } \\
\text { agree }\end{array}$ & $\begin{array}{ll}\text { o } & \text { I have taken care of infant siblings } \\
\text { o } & \text { I have been a babysitter for infants } \\
\text { o } & \text { I am familiar with handling infants } \\
\text { o } & \text { I have not dared to touch infants } \\
\text { o } & \text { I am frightened to handle infants } \\
\text { o } & \text { I feel tense when handling infants } \\
\text { o } & \text { I think I manage with infants } \\
\text { o } & \text { I am waiting for handling infants }\end{array}$ \\
\hline $\begin{array}{l}\text { Working as practitioners, } \\
\text { Cross the right answers }\end{array}$ & $\begin{array}{l}\text { O I have not worked as a physician } \\
\text { o I have worked as a physician in hospitals } \\
\text { o I have worked as a physician in health care centres }\end{array}$ \\
\hline $\begin{array}{l}\text { Interest in pediatrics, } \\
\text { Cross if you agree }\end{array}$ & o I am interested pediatrics as a career choice \\
\hline $\begin{array}{l}\text { Open question; } \\
\text { Write the answer }\end{array}$ & $\begin{array}{l}\text { What kind of knowledge or teaching you wish to have } \\
\text { about meeting, caring or treating infants? }\end{array}$ \\
\hline
\end{tabular}




\subsection{Background}

Most of the medical students $(146 ; 63.8 \%$ vs. $156 ; 65.7 \%)$ came from the University Hospital area in Northern Finland. Of the remaining students, 19 (8.3\%) vs. $17(7.2 \%)$ did not reveal their origin.

Seventeen $(7.4 \%)$ of students in the Cohort 1 and $13(5.5 \%)$ in the Cohort 2 were the only offspring in their families. Eighty-three (36.2\%) of the students in the Cohort 1 had two, 59 (25.8\%) had three, 32 (14.0\%) had four, $15(6.6 \%)$ had five and $22(9.6 \%)$ had more siblings in their native families. The corresponding percentages for the Cohort 2 were 80 (33.6\%), 75 (31.5\%), 28 (11.8\%), 18 (7.7\%) and $18(7.7 \%)$, respectively.

Eighteen ( 9 male and 9 female) (7.9\%) students in the Cohort 1 had a total of 35 of their own children, and 21 (13 male and 8 female) (8.9\%) students in the Cohort 2 had the same.

The ages of the students in the Cohort 1 ranged between 22 and 43 and in the Cohort 2 between 22 and 39 years. The mean ages (SD) of the students were 25.1 (3.0) years in the Cohort 1 and 25.9 (3.0) years in the Cohort 2 ( $\mathrm{p}=0.040)$. The mean age $(\mathrm{SD})$ of the females between the Cohorts changes significantly from 24.8 (2.9) to $26.1(3.2)$ years $(\mathrm{p}=0.001)$ but the mean age (SD) of the males stayed (25.6 (3.1) vs. 25.7 (2.7) years).

\subsection{Common Care and Handling}

Experiences of detailed infant care and handling results are shown as percentage bars in the Figure 1. Two thirds of the students in both cohorts (no gender difference) had never bathed an infant (Figure 1(A)). The male students, however, represented most often those students who had never dressed an infant or changed a nappy (Figure 1(A) and Figure 1(B)). Also the amount of males who had never held infants in lap increased between the Cohorts (Figure 1(B)). The most common alternative procedure for students was holding in the lap, where repetitions of over five times were reported by two thirds of the students in both Cohorts (Figure 1(C)). The percent for males decreased and for females increased producing gender difference in the second cohort (Figure 1(C) and Figure 1(D)). The female students had changed nappies over 5 times significantly more often than males in both groups (Figure $1(C)$ ). Female students had repeatedly dressed infants significantly more frequently than male students in both Cohorts (Figure 1(C) and Figure 1(D)). But the males increased there significantly in ten years (Figure $1(\mathrm{D})$ ).

Eighty-six (37.9\%) of the students in the Cohort 1 (52.1\% of the males and $31.2 \%$ of the females) had never fed infants. Correspondingly, 91 (38.5\%) of the students in the Cohort 2 neither had fed infants $(49.1 \%$ of the males and $28.3 \%$ of the females). The difference between genders was significant (Cohort $1: \mathrm{p}=$ 0.003 and Cohort 2: $\mathrm{p}=0.001)$. However, 120 (52.9\%) of the students in the Cohort 1 (35.6\% of the males and $61.0 \%$ of the females) and $142(60.2 \%)$ of the students in the Cohort 2 (49.1\% of the males and $70.8 \%$ of the females) had bottle-fed, with a significant difference between the genders $(p<0.001$ in both 
Cohorts). Furthermore, 120 (52.9\%) of the students in the Cohort 1 (43.8\% of the males and $57.1 \%$ of the females, $\mathrm{p}=0.066)$ and $128(54.2 \%)$ of the students in the Cohort 2 (44.0\% of the males and $54.2 \%$ of the females, $\mathrm{p}=0.003$ ) had given solid food, respectively.

\subsection{Experiences, Attitudes and Expectations}

The responses to the questions concerning experiences, attitudes and expectations are shown as percentage bars in Figure 2.

The female students were far more experienced than male students in babysitting in both the Cohorts. However, they more often than males considered it a little frightening to handle infants especially in the Cohort 1. Despite that female students wished to handle infants more eagerly than male students in both Cohorts. The difference in male students' belief to be able to manage with infants diminished in ten years in comparison to female students. Students' own

A: Never $(\%)$

Cohort 1 Cohort 2






\section{C: Over five times $(\%)$ \\ Cohort 1 Cohort 2}



Holding in lap

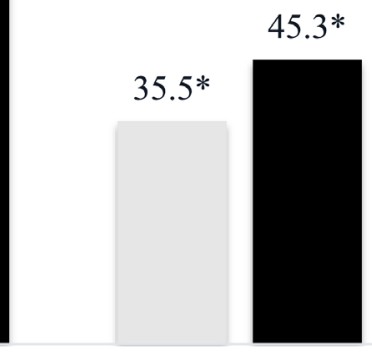

Dressing an infant

Changing a nappy

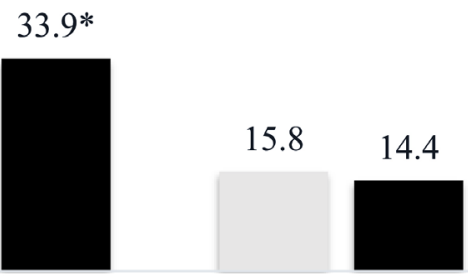

Bathing an infant

D: Over five times $(\%)$

Cohort $1 \mathrm{M} \backsim$ Cohort $2 \mathrm{M} \backsim$ Cohot $1 \mathrm{~F} \backsim$ Cohort $2 \mathrm{~F}$

$79.2^{*}$

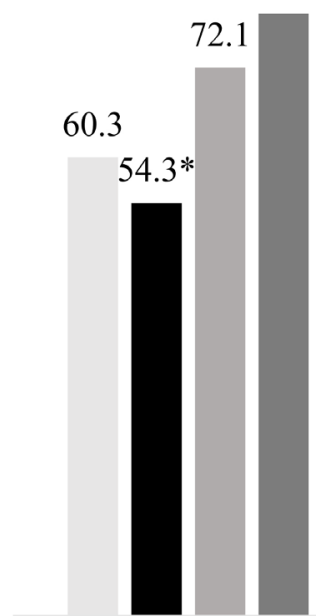

Holding in lap

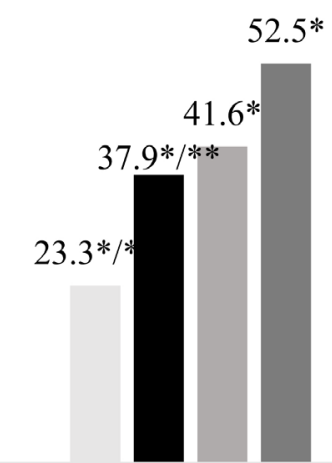

Dressing an infant

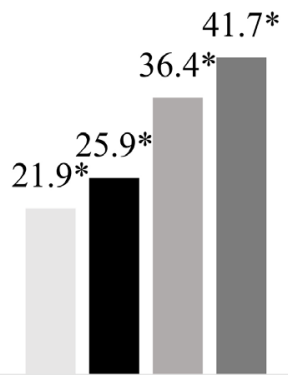

Changing a nappy

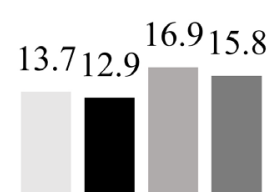

Bathing an infant

Figure 1. Experiences of infant care among medical students in cohort years 2004-2206 (C1) and 2014-1015 (C2). Frequencies of active care procedures (never or over five times) are shown as percentage bars of students. (A): Percentages of never for students in cohorts. (B): Separate percentages of never for male (M) and female (F) genders in cohorts. (C): Percentages of over five times for students in cohorts. (D): Separate percentages of over five times for genders in cohorts. Chi-Square Tests: $p$-value $<0.050 *$ for differences between male and female students inside the cohorts 1 or 2 and ${ }^{\star *}$ for differences of the same gender between the cohorts.

believes to manage in handling infants increased significantly with students getting older in both Cohorts ( $\mathrm{p}<0.001$ vs. $\mathrm{p}=0.019$ ).

Two hundred and twenty (96.1\%) of the students in the Cohort 1 and 223 

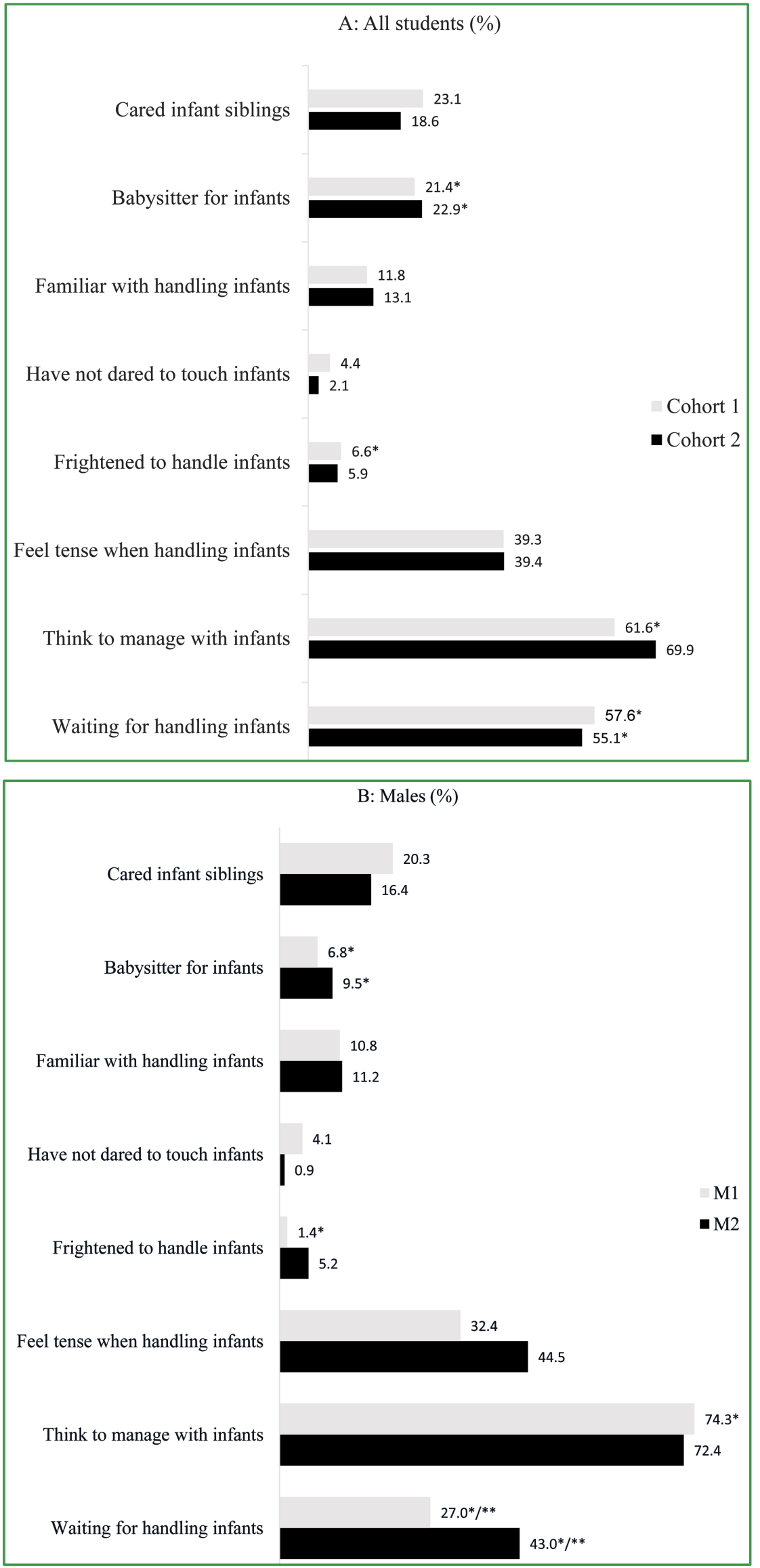


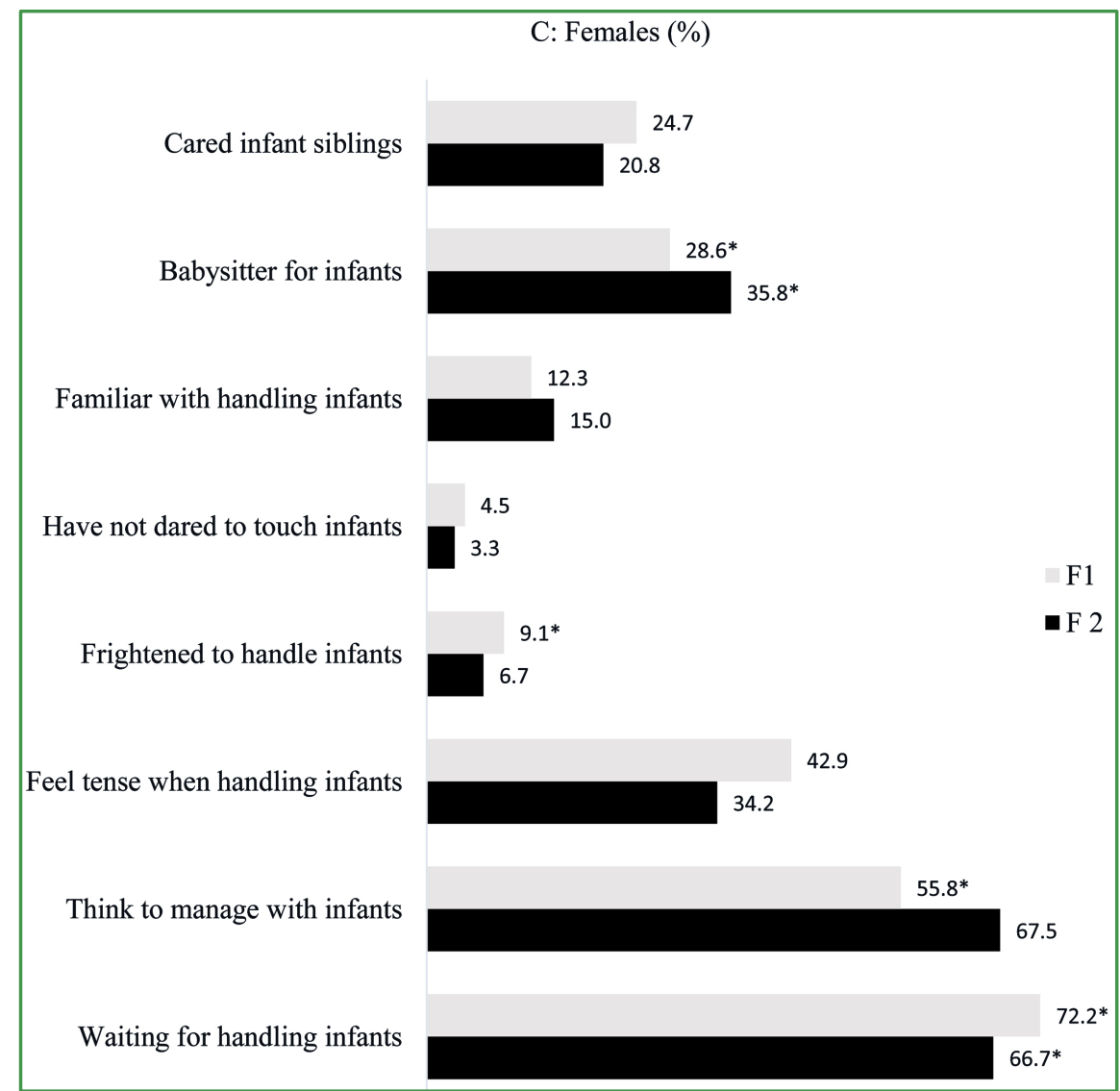

Figure 2. The positive answers of medical students in the cohort years 2004-2006 (Cohort 1) and 2014-1015 (Cohort 2) to questions of their experiences, attitudes and expectations in regard to infants are shown as percentages. (A): Percentages between the cohorts. (B): Percentages for males in the cohorts (M1 and M2) (C): Percentages for females in the cohorts (F1 and F2). Fishers's Exact Tests: $\mathrm{p}<0.050{ }^{\star}$ for differences between male and female students inside the cohorts 1 or 2 ; ${ }^{* \star}$ for differences of the same gender between the cohorts.

(94.5\%) in the Cohort 2 had worked in a healthcare environment before paediatrics courses. Thirty-one (13.5\%) of the students in the Cohort 1 and 120 (52.9\%) of the Cohort 2 had worked in hospitals and correspondingly, 205 (89.5\%) vs. 74 (31.3\%) in healthcare centres before coming to paediatric courses.

Sixty-nine $(30.3 \%)$ of the students $(23.0 \%$ of the males and $33.8 \%$ of the females) in the Cohort 1 and respectively, 52 (22.0\%:19.8\% of the males and $24.2 \%$ of the females) in the Cohort 2 reported an interest in paediatrics as a possible future career.

\subsection{Preferences Regarding Teaching}

In free comments, 68 (29.7\%) of the students in the Cohort 1 and $122(51.7 \%)$ in the Cohort 2 wrote their wishes for the course. They wanted first of all to handle as many neonates and infants as possible, to learn to examine infants, and to become familiar with their features. Students especially wished to learn to distinguish sick from healthy infants. 


\subsection{Discussion}

Medical students came mainly from families with more than one offspring. Two thirds of the students had held infants in their laps more than five times, but two thirds of students had never bathed an infant with no change in ten years. One third of the students had never fed an infant, but a half of the students had given solid food in both cohorts. The students mainly expected to manage with young infants although many of them felt frightened or tense. Almost all the students in both cohorts had worked in a healthcare before their paediatrics courses. One third of the first cohort reported an interest in paediatrics as a career choice, but only one fifth in the second cohort. One third of the Cohort 1 and a half of the Cohort 2 indicated a wish to see and assess as many neonates and young infants as possible. They especially wanted to learn to distinguish sick from healthy infants.

Although two thirds of the students had held an infant in their laps, only one third of them were familiar with everyday procedures such as changing nappies. However, dressing of infants showed increasing numbers both in males and females. The increase in the amount of male students with own children and the increased age of female students may have effects on that. Furthermore, half of the students had given solid food to infants, but more than a third had never fed an infant with no change in ten years. An empirical research has evidenced that direct patient contacts for only 1-day by the guidance of an interactive nurse can increase basic child care experiences in medical students significantly in comparison to not guided students. For instance, percentage for bottle feeding increased from $11 \%$ to $55 \%$ and bathing the child from $2 \%$ to $36 \%$. [1]

Male students were more self-confident, less frightened and less sensitive than female students, especially in the Cohort 1 , in their responses concerning managing with infants, although female students were more experienced. A videotaped objective structured clinical examination study has shown that female students consistently report decreased self-confidence and increased anxiety related to their competence [2]. According to meta-analyses female medical students underestimate their performance more often than male students [3]. Supposedly encouragement, training and positive feedback could be the best practices to work out one's competence. It has been suggested that extra years of life experience before studies could improve social factors important to personal development [4]. Theoretically such extra years may have helped here, because reports of familiarity with the care increased significantly with the age of the students.

A large answering percentage of medical students show they are motivated to reflect their feelings and experiences of infants and willing to express wishes in teaching. The Cohort 1 consisted of five courses and the second of four reflecting rising numbers of medical students. According to reports, valuable practical clinical skills among new medical trainees or residents in hospitals are declining [5] [6]. The main reason for this has been supposed to be a lack of clinical skills 
teaching in medical schools [5] [6]. The increased numbers of medical students place a question, what is adequate amount of clinical teaching and how we can offer teaching enough in clinical patient contacts. Clinical education in the ward is very valuable for medical students, who gain experience of examination, caring and communication [7] [8]. It is known that patient experiences affect medical students' learning by providing insight into real problems [8] [9] [10] [11]. Bed side teaching in medical education has inspired to new thinking of executive possibilities. As an implementation to that residents and interns of staff members have been used more as bedside teachers to students [12].

This study has some limitations. The questionnaire we used here has not been validated in different populations. However, we used reliable simple questions that are easy to answer with straightforward interpretation [1]. The students' experiences with older children were not evaluated, which may have influenced the answers in both of the cohorts. For comparability, the amounts of students for the cohort 2 were based on the number of students in the cohort 1 , and both of the cohorts included consecutive courses. We did not consider the effect of previous university studies before entering medical school, and that might have had an impact on the answers. However, in Finland, all the students entering medical school have gone through at least 12 years of education.

It seems here that the denial of permission to work as an independent practitioner in health care centres before clinical paediatrics courses did not decrease experiences of young infant contacts, neither changed many attitudes or expectations among undergraduate medical students. Most of the medical students had worked as practitioners, mainly in healthcare centres in the Cohort 1 and in hospitals in the Cohort 2. During their four-year studying they have attended clinical courses in otorhinolaryngology, ophthalmology and dermatology, among other subjects, which are matters useful to paediatrics. Young infants, healthy or sick, may be very challenging. Medical students no doubt need training and experience when it comes to examining sick children [13]. Over half of the students in the Cohort 2 mentioned it very important to assess as many infants as possible during courses to learn to distinguish sickness in infants.

One third of the medical students in the Cohort 1 and one fifth in the Cohort 2 (females more frequently than males) indicated an interest in paediatrics as a future career choice at the beginning of their paediatrics courses. Paediatrics has elsewhere been preferred by $7 \%-28 \%$ of female students and by $1 \%-16 \%$ of male students [14]. Our male students rated their interest higher.

\section{Conclusion}

Self-reported experiences of medical students in handling and care of infants are quite low before their paediatric courses. The denial not to be able to work as independent practitioner in health care centres before paediatric courses seems not to change experiences. Students need supportive guidance and encouragement to handle infants. Medical students are willing to learn and have experiences in practice. 


\section{References}

[1] Walter, R.S., Trzcinski, K.M., Lawrence, J.S. and Simonetti, R.M. (1997) Pediatric Registered Nurses as Preceptors for 3rd-Year Medical Students: A Program to Enhance the Pediatric Inpatient Experience. Teaching and Learning in Medicine, 9, 91-95. https://doi.org/10.1080/10401339709539821

[2] Blanch, D.C., Hall, J.A., Roter, D.L. and Frankel, R.M. (2008) Medical Student Gender and Issues of Confidence. Patient Education and Counseling, 72, 374-381.

[3] Blanch-Hartigan D. (2011) Review: Medical Students' Self-Assessment of Performance: Results from Three Meta-Analyses. Patient Education and Counseling, 84, 3-9.

[4] Shacklady, J., Holmes, E., Mason, G., Davies, J. and Dornan, T. (2009) Maturity and Medical Students' Ease of Transition into the Clinical Environment. Medical Teacher, 31, 621-626. https://doi.org/10.1080/01421590802203496

[5] Ramani, S., Ring, B.N., Lowe, R., Ring, B.N., Lowe, R. and Hunter, D. (2010) A Pilot Study of Assessing Knowledge of Clinical Signs and Physical Examination Skills in Incoming Medicine Residents. The Journal of Graduate Medical Education, 2, 232 235. https://doi.org/10.4300/JGME-D-09-00107.1

[6] Verghese, A. (2010) Beyond Measure: Teaching Clinical Skills. The Journal of Graduate Medical Education, 2, 1-3. https://doi.org/10.4300/JGME-D-10-00008.1

[7] Nadolski, G.J., Bell, M.A., Brewer, B.B., Frankel, R.M., Cushing, H.E., and Brokaw, J.J. (2006) Evaluating the Quality of Interaction between Medical Students and Nurses in a Large Teaching Hospital. BMC Medical Education, 6, 23. https://doi.org/10.1186/1472-6920-6-23

[8] Williams, K.N., Ramani, S., Fraser, B. and Orlander, J.D. (2008) Improving Bedside Teaching: Findings from a Focus Group Study of Learners. Academic Medicine, 83, 257-264. https://doi.org/10.1097/ACM.0b013e3181637f3e

[9] Dornan, T. and Bundy, C. (2004) What Can Experience Add to Early Medical Education? Consensus Survey. BMJ, 329, 834-837.

https://doi.org/10.1136/bmj.329.7470.834

[10] Littlewood, S., Ypinazar, V., Margolis, S.A., Scherpbier, A., Spencer, J. and Dornan, T. (2005) Early Practical Experience and the Social Responsiveness of Clinical Education: Systematic Review. BMJ, 331, 387-391. https://doi.org/10.1136/bmj.331.7513.387

[11] Noor, S., Batra, S. and Byrne, A. (2011) Learning Opportunities in the Clinical Setting (LOCS) for Medical Students: A Novel Approach. Medical Teacher, 33, e193e198. https://doi.org/10.3109/0142159X.2011.557413

[12] Peters, M. and ten Cate, O. (2014) Bedsite Teaching in Medical Education: A Literature Review. Perspectives on Medical Education, 3, 76-88.

https://doi.org/10.1007/s40037-013-0083-y

[13] Craze, J. and Hope, T. (2006) Teaching Medical Students to Examine Children. Archives of Disease in Childhood, 91, 966-968. https://doi.org/10.1136/adc.2005.092502

[14] Alers, M., van Leerdam, L., Dielissen, P. and Lagro-Janssen, A. (2014) Gendered Specialities during Medical Education: A Literature Review. Perspectives on Medical Education, 3, 163-178. https://doi.org/10.1007/s40037-014-0132-1 
Submit or recommend next manuscript to SCIRP and we will provide best service for you:

Accepting pre-submission inquiries through Email, Facebook, LinkedIn, Twitter, etc. A wide selection of journals (inclusive of 9 subjects, more than 200 journals)

Providing 24-hour high-quality service

User-friendly online submission system

Fair and swift peer-review system

Efficient typesetting and proofreading procedure

Display of the result of downloads and visits, as well as the number of cited articles Maximum dissemination of your research work

Submit your manuscript at: http://papersubmission.scirp.org/

Or contact ijcm@scirp.org 